\title{
Study on the decolourisation conditions of methylene blue by Irpex Lacteus
}

\author{
Hongshi BU ${ }^{1}$, Huan WANG ${ }^{2}$, Bo ZHANG ${ }^{1}$, Xin DONG ${ }^{1}$, Jia WANG ${ }^{1}$, Tianyi ZHAO ${ }^{1}$, Shumin WANG ${ }^{1, *}$ \\ ${ }^{1}$ College of Pharmacy, Changchun University of Chinese Medicine, Changchun, Jilin, 130117, China \\ ${ }^{2}$ Ginseng Science Research Institute, Changchun University of Chinese Medicine, Changchun, Jilin, 130117, China
}

\begin{abstract}
The fungus Irpex Lacteus is effective in decolourising methylene blue, a common dye in printing and dyeing wastewater, and it is of clear significance to investigate its optimal decolourisation process through liquid fermentation. The medium mixed with methylene blue dye was incubated with Irpex Lacteus in a constant temperature shaking flask liquid fermentation equipment, and single factors such as incubation time, temperature, shaking bed speed, dye concentration, $\mathrm{pH}$, carbon and nitrogen sources were screened, and key factors were targeted orthogonal tests were carried out to optimise the best decolourisation process for Irpex Lacteus against methylene blue. The single-factor test revealed that carbon, nitrogen, $\mathrm{pH}$ and inoculum were the main factors influencing the decolourisation of methylene blue by Irpex Lacteus. The results of the orthogonal test showed that the decolourisation effect was best when the carbon source was sucrose, the nitrogen source was peptone, $\mathrm{pH}=3.5$, the inoculum level was $7 \%$ and the incubation time was 10 days. Irpex Lacteus showed good decolourisation effect on methylene blue and the optimised process conditions provided a new direction for the treatment of printing and dyeing wastewater.
\end{abstract}

\section{Introduction}

China is a large textile printing and dyeing country, and the huge population is driving the rapid development of the textile manufacturing industry. The consequent problems of dyeing and printing wastewater treatment are becoming increasingly prominent, seriously affecting the surrounding environment, while the huge amount of money consumed for wastewater treatment is restricting the pace of development of large industries [1]. The current treatment methods for printing and dyeing wastewater include chemical, biological and physical methods, of which the biological method has been highly respected in recent years for its resource-saving, excellent effect and non-secondary pollution characteristics [2].

Irpex Lacteus Fr. is a rare medicinal fungus belong to the family polyporaceae, which is produced exclusively deep in the dense forests of Changbai Mountain in Jilin Province, and has good immunomodulatory effects, it is also a fungus with biodegradability for dye wastewater pollution [3]. The study was conducted to investigate the optimal decolorization conditions (carbon source, nitrogen source,) and environmental conditions (inoculum, dye concentration, incubation time, incubation temperature, $\mathrm{pH}$ ) for methylene blue using the biofermentation model of Irpex Lacteus.

\section{Materials and methods}

\subsection{Decolorization rate inspection}

The medium was sterilized (autoclaved at $121^{\circ} \mathrm{C}$ for 30 $\mathrm{min})$. The uninoculated medium was prepared as a blank group, and the medium after inoculation with Irpex Lacteus was placed in a constant temperature shaker for shaking. After a certain number of days of incubation, the medium was centrifuged at $8000 \mathrm{r} / \mathrm{min}$ for $10 \mathrm{~min}$, and the supernatant was taken and the absorbance was measured at $660 \mathrm{~nm}$ using a UV spectrophotometer, and the decolourisation rate was calculated according to the following formula:

Decolorization rate $=) \mathrm{A}_{0}-\mathrm{A}_{\mathrm{C}}\left(/ \mathrm{A}_{0} \times 100 \%\right.$

$\left(\mathrm{A}_{0}\right.$ : Absorbance of the dye medium in the blank group, $A_{C}$ : Absorbance of dye media cultured after inoculation)

\subsection{Examination of the number of days of decolorization incubation}

The incubation was carried out according to 2.1 and the decolorization effect of Irpex Lacteus after 7, 8, 9, 10, 11 and 12 days of incubation was examined. The mean values were taken twice in parallel for each group and the results of each test were compared to select the best number of days of incubation.

\footnotetext{
${ }^{*}$ Corresponding author: wangsm@ccucm.edu.cn
} 


\subsection{Examination of carbon and nitrogen sources}

Cultivate Irpex Lacteus according to 2.1, select equal proportions of sucrose, maltose, lactose, glucose, beef paste, urea, peptone and yeast extract for carbon and nitrogen source investigation, incubate for 10 days, parallel 2 times for each group of experiment, select the best carbon and nitrogen source.

\subsection{Examination of inoculum doses}

The inoculum levels of $1 \%, 3 \%, 5 \%, 7 \%$ and $9 \%$ were selected for examination according to the method in 2.1 and incubated for 10 days, with each group of experiments being performed twice in parallel to select the best inoculum level according to the decolorization rate.

\subsection{Examination of the initial dye concentration}

According to the method in 2.1, media with dye concentrations of $5 \mathrm{mg} / \mathrm{L}, 10 \mathrm{mg} / \mathrm{L}, 15 \mathrm{mg} / \mathrm{L}, 25 \mathrm{mg} / \mathrm{L}$, $30 \mathrm{mg} / \mathrm{L}$, were configured for inoculation with Irpex Lacteus for decolourisation investigation, and incubated for 10 days, and each group of experiments was conducted twice in parallel to select the best dye concentration according to the decolourisation rate.

\subsection{Examination of the initial $\mathrm{pH}$ of the medium}

Following the method in 2.1, media with $\mathrm{pH}$ values of $2.5,3,3.5,4,4.5,5,5.5,6,7$ and 8 were configured for inoculation with Irpex Lacteus for investigation and incubation for 10 days, with 2 parallel experiments in each group to select the best $\mathrm{pH}$ value according to the decolourisation rate.

\subsection{Orthogonal experiment for decolourisation of Bacillus sp.}

L9 $\left(3^{4}\right)$ orthogonality was used to optimize the decolourisation of methylene blue by B. albicans. According to the results of the single-factor experiment, Irpex Lacteus was cultivated in accordance with the method in 2.1, for a certain number of days, and the results of each group were compared to determine the best decolourisation conditions for methylene blue by Irpex Lacteus.

\section{Results}

\subsection{Results of experiments examining the number of days of incubation}

The normal growth cycle of Irpex Lacteus is generally 10 days, when added to the dye after the white rake teeth bacteria culture, from Figure 1 can be seen, the decolourisation rate of methylene blue in 7 to 10 days gradually increased, in 10 days reached $73.363 \%, 10$ days after the decolourisation rate gradually tends to stabilize. Therefore, it was determined that the decolourisation of methylene blue by Irpex Lacteus was the best when the culture time reached 10 days.

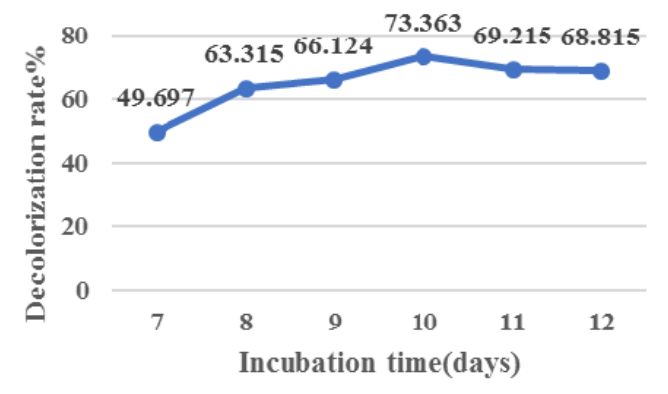

Figure 1. Effect of incubation time on the decolorization of Irpex Lacteus

\subsection{Examination of carbon and nitrogen sources}

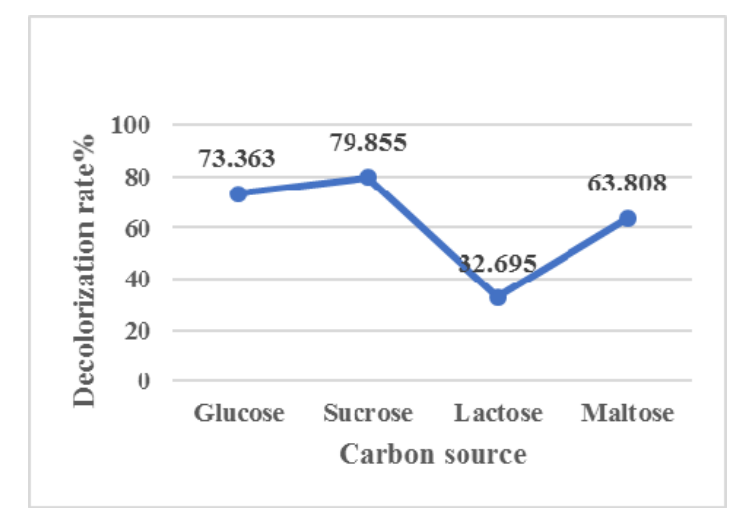

Figure 2. Effect of carbon source on the decolourisation effect

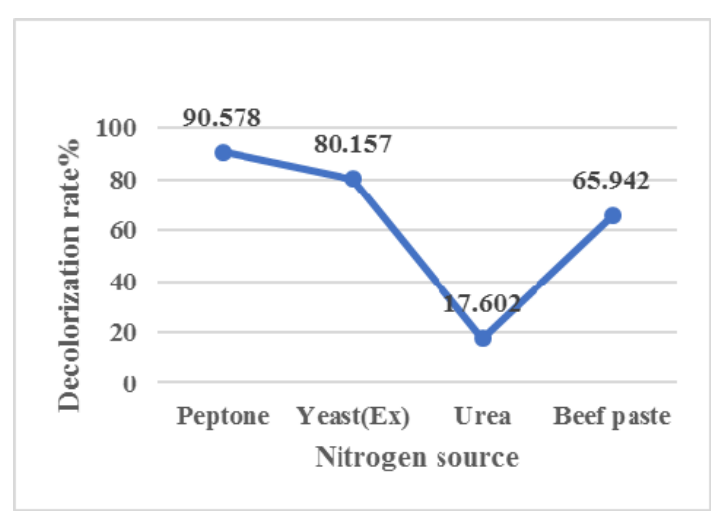

Figure 3. Effect of nitrogen source on the decolourisation effect

From Figure 2 and Figure 3, it can be seen that different carbon and nitrogen sources have a more significant effect on the decolourisation rate of Irpex Lacteus. The most suitable carbon source for decolourisation of methylene blue by Irpex Lacteus is sucrose and the nitrogen source is peptone. 


\subsection{Inoculation study experiment}

Table 1 Orthogonal tests and results of decolorization conditions

\begin{tabular}{|c|c|c|c|c|c|}
\hline \multirow{2}{*}{ Experiment } & \multicolumn{3}{|c|}{ Factors } & \multirow{2}{*}{ Decolorization rate\% } \\
\cline { 2 - 5 } & Concentration $(\mathrm{mg} / \mathrm{L})$ & Time (days) & $\mathrm{pH}$ & Inoculum\% & 89.3 \\
\hline 1 & 30 & 9 & 3 & 5 & 94.86 \\
\hline 2 & 30 & 10 & 3.5 & 7 & 86.73 \\
\hline 3 & 30 & 11 & 4 & 9 & 94.03 \\
\hline 4 & 35 & 9 & 3.5 & 9 & 85.42 \\
\hline 5 & 35 & 10 & 4 & 5 & 91.25 \\
\hline 6 & 35 & 11 & 3 & 7 & 86.88 \\
\hline 7 & 40 & 9 & 4 & 7 & 90.57 \\
\hline 8 & 40 & 10 & 3 & 9 & 93.41 \\
\hline 9 & 40 & 11 & 3.5 & 5 & \\
\hline Avg 1 & 90.297 & 90.07 & 90.373 & 90.377 & \\
\hline Avg 2 & 90.233 & 90.283 & 94.1 & 90.997 & \\
\hline Avg 3 & 90.287 & 90.463 & 86.343 & 90.443 & \\
\hline Range & 0.064 & 0.393 & 7.757 & 1.62 & \\
\hline
\end{tabular}

Table 2 Analysis of variance for orthogonal test results

\begin{tabular}{|c|c|c|c|c|c|}
\hline Factors & Q & DF & F ratio & F criticality & Significance \\
\hline Concentration & 0.007 & 2 & 1 & 19 & \\
\hline Time & 0.233 & 2 & 33.286 & 19 & $*$ \\
\hline $\mathrm{pH}$ & 90.295 & 2 & 12899.286 & 19 & $*$ \\
\hline Inoculum & 4.068 & 2 & 581.143 & 19 & $*$ \\
\hline Errors & 0.01 & 2 & & & \\
\hline
\end{tabular}

From Figure 4, the following conclusion can be drawn: with the increasing amount of inoculum, the decolourisation rate gradually increases, and the best decolourisation effect is presented around $7 \%$.

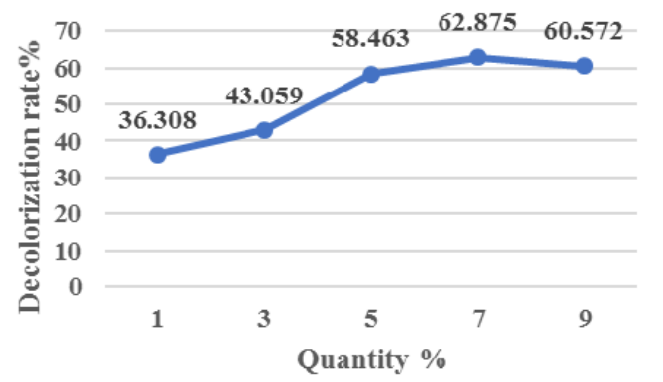

Figure 4. Effect of inoculum level on the decolourisation effect of Irpex Lacteus

\subsection{Experiment to examine the concentration of dyes}

As shown in Figure 5, the decolourisation rate increased as the dye concentration continued to rise, and after the dye concentration reached $25 \mathrm{mg} / \mathrm{L}$, the growth trend gradually began to level off, and after $35 \mathrm{mg} / \mathrm{L}$, the decolourisation rate began to stabilize at around $80 \%$.

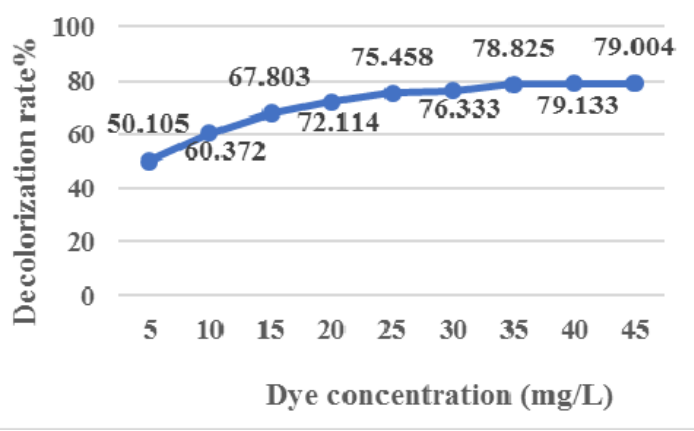

Figure 5. Effect of dye concentration on decolourisation of Irpex Lacteus

\subsection{Examination of the $\mathrm{pH}$ of the culture medium}

As can be seen in Figure 6, the decolourisation rate of Irpex Lacteus increased with increasing $\mathrm{pH}$, reaching a maximum decolourisation rate of $78.486 \%$ at $\mathrm{pH}=3.5$. When the $\mathrm{pH}$ was greater than 3.5 , the decolourisation rate of Irpex Lacteus continued to decrease with increasing $\mathrm{pH}$.

The reason for the trend in the graph is that when the $\mathrm{pH}$ is too high or too low, the growth of Irpex Lacteus is inhibited and the decolourisation rate is reduced, whereas 3.5 is the most suitable environment for the growth of Irpex Lacteus to have the maximum decolorization rate. 


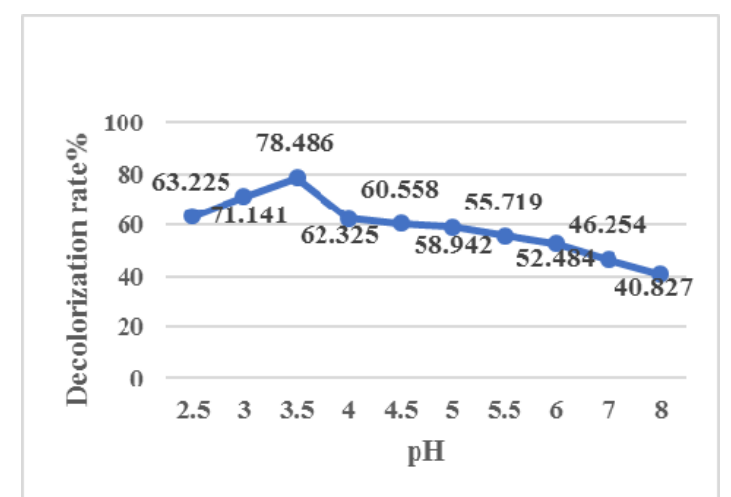

Figure 6. Effect of $\mathrm{pH}$ on the decolourisation rate of Irpex Lacteus

\subsection{Irpex Lacteus orthogonal experiment for optimum decolourisation conditions}

According to the orthogonal table 1, concentration, time, $\mathrm{pH}$ and inoculum were selected for the decolorization of Irpex Lacteus, and the results of the orthogonal analysis of variance showed that the order of factors affecting the decolourisation of Irpex Lacteus was $\mathrm{pH}>$ inoculum $>$ time $>$ concentration, with $\mathrm{pH}$ having a particularly significant effect on Irpex Lacteus. From this analysis it can be concluded that the optimum decolourisation conditions for Irpex Lacteus were an initial concentration of $30 \mathrm{mg} / \mathrm{L}$ for 10 days, a pH of 3.5 and an inoculum of $7 \%$, under which the decolourisation rate of Irpex Lacteus was $94.86 \%$.

\section{Discussion}

The nutrients and culture conditions of the fermentation medium are the main factors affecting the decolorization of Irpex Lacteus, therefore the optimization of the nutrients and culture conditions of the Irpex Lacteus medium is one of the main routes to improve the decolorization of Irpex Lacteus, the decolorization rate of Irpex Lacteus could reach about $80 \%$ with sucrose as the carbon source and about $90 \%$ with peptone as the nitrogen source. $\mathrm{pH}$ is a parameter that requires critical control during fungal growth and fermentation and also has an important impact on the decolorization method for non-fungal species [4], with optimal growth under acidic conditions, which has a key impact on methylene blue decolorization. As excessive inoculum dilutes the concentration of methylene blue volumetrically, control of the inoculum is key to ensuring the accuracy of the experiment, and also from a resource conservation point of view, incubation time is as dominant as inoculum size [5]. In terms of dye concentration, the degradation capacity of Irpex Lacteus tended to be maximized when the concentration of methylene blue in the medium reached $40 \mathrm{mg} / \mathrm{L}$ and subsequent increases in dye concentration did not negatively affect the degradation of Irpex Lacteus, which had a high capacity for dye degradation and stable viability.

\section{Conclusion}

The optimal fermentation process was obtained by using the orthogonal experimental design method to optimize the culture and process of Irpex Lacteus, namely: sucrose $30 \mathrm{~g} / \mathrm{L}$, peptone $20 \mathrm{~g} / \mathrm{L}, \mathrm{KH}_{2} \mathrm{PO}_{4} 2 \mathrm{~g} / \mathrm{L}, \mathrm{MgSO}_{4}$ $1.5 \mathrm{~g} / \mathrm{L}$; culture conditions: initial $\mathrm{pH} 3.5$, inoculum $7 \%$, dye concentration $30 \mathrm{mg} / \mathrm{L}$, culture time 10 days. The incubation conditions were: initial $\mathrm{pH} 3.5$, inoculum $7 \%$, dye concentration $30 \mathrm{mg} / \mathrm{L}$, incubation time 10 days, the decolorization rate of Irpex Lacteus could reach over $94 \%$ under these conditions. The optimization of good decolorization conditions for Irpex Lacteus is of great relevance to reduce industrial maintenance costs and the environmental burden.

\section{References}

1. R. Nayak, T. Panwar and L. V. T. Nguyen, in Sustainable Technologies for Fashion and Textiles, R. Nayak Editor, p. 3, Woodhead Publishing (2020).

2. S. Vaish and B. Pathak, in Biotechnological Utilization of Mangrove Resources, J. K. Patra, R. R. Mishra and H. Thatoi Editors, p. 399, Academic Press (2020).

3. K. Malachova, Z. Rybkova, H. Sezimova, J. Cerven and C. Novotny, Water Res., 47, 7143 (2013).

4. J. Racyte, M. Rimeika and H. Bruning, Environment Protection Engineering 35 (2009) 3, 35 (2009).

5. B. Sadaqat, N. Khatoon, A. Y. Malik, A. Jamal, U. Farooq, M. I. Ali, H. He, F.-J. Liu, H. Guo, M. Urynowicz, Q. Wang and Z. Huang, Scientific Reports, 10, 20240 (2020). 